\title{
Clinical significance of elevated serum A-FABP and free fatty acid in neonates with hypoxic ischemic brain damage
}

\author{
MEI LI ${ }^{1}$, LIAN JIANG ${ }^{1}$, HUIFEN ZHANG $^{1}$, DANDAN WANG $^{2}$, MIN ZHANG $^{3}$ and LIANSHAN ZHANG ${ }^{3}$ \\ ${ }^{1}$ Department of Pediatrics, Fourth Hospital of Hebei Medical University, Shijiazhuang, Hebei 050011; \\ ${ }^{2}$ Department of Pathology, Wuxi Maternal and Child Health Hospital, Wuxi, Jiangsu 214002; \\ ${ }^{3}$ Basic Medical College, Hebei Medical University, Shijiazhuang, Hebei 050017, P.R. China
}

Received March 29, 2016; Accepted May 27, 2016

DOI: $10.3892 /$ etm.2016.3411

\begin{abstract}
The main function of adipocyte fatty acid-binding protein (A-FABP) is to regulate fatty acid metabolism as its molecular chaperone. The clinical significance of A-FABP in hypoxic-ischemic brain damage (HIBD) neonates is not yet clear. Free fatty acid (FFA) in cerebral cortex increases along with hypoxia ischemia degree. Thus, we aimed to investigate whether FFA can induce A-FABP expression and elevate the serum A-FABP level in HIBD neonates. In the present study, 42 HIBD neonates were selected including 11 cases as mild, 16 cases as moderate and 15 cases as severe. The serum was collected from peripheral vein at $72 \mathrm{~h}$ after the first visit (acute stage) and 7 days after birth (recovery stage), and the serum from 10 normal neonates was used as the control. The serum level of A-FABP and FFA in 42 neonates with acute phase and recovery phase HIBD were detected using ELISA and copper colorimetric method. The overall serum A-FABP content in HIBD neonates at the acute stage was significantly higher compared to the normal neonates $(\mathrm{P}<0.05)$. The serum A-FABP level in severe HIBD neonates was significantly higher than that in mild HIBD, moderate HIBD and normal neonates $(\mathrm{P}<0.05)$. The serum FFA level in HIBD neonates at the acute stage was $1,521.57 \pm 605.63 \mu \mathrm{mol} / 1$, which was significantly higher than that in the normal neonates 838.24 $\pm 294.22 \mu \mathrm{mol} / 1$. The serum FFA levels in mild, moderate and severe HIBD neonates were significantly higher than those in the normal neonates. The overall A-FABP level in HIBD neonates at the recovery stage was significantly lower compared to the acute stage, which was significant in severe HIBD neonates. A-FABP levels in mild and moderate HIBD
\end{abstract}

Correspondence to: Dr Lianshan Zhang, Basic Medical College, Hebei Medical University, 361 East Zhongshan Road, Shijiazhuang, Hebei 050017, P.R. China

E-mail: lianshanzh@163.com

Key words: hypoxic ischemic brain damage, adipocyte fatty acid-binding protein, neonate, free fatty acid, enzyme-linked immunosorbent assay neonates at recovery stage were decreased compared with the acute stage, although there was no statistical difference. There was a positive correlation between serum A-FABP and FFA in HIBD neonates at acute stage $(r=0.369, \mathrm{P}<0.05)$. In conclusion, serum A-FABP and FFA levels were signifcantly increased in HIBD neonates at acute stage, and were positively correlated. The serum A-FABP level in HIBD neonates at recovery stage was significantly lower than that in the acute stage. The results suggested that serum A-FABP and FFA levels at acute stage can reflect the severity of HIBD. The detection of serum A-FABP and FFA can be applied as indicators for the early diagnosis of HIBD, but also provides a basis for the clinical evaluation of HIBD treatment.

\section{Introduction}

Hypoxic-ischemic brain damage (HIBD) in neonates involves the cerebral injury of fetus and neonates caused by partial or complete hypoxia, cerebral blood flow reduction or pause, which is caused by perinatal asphyxia (1). HIBD often occurs within $24 \mathrm{~h}$ after birth, and the occurrence rate of hypoxic ischemic encephalopathy (HIE) in neonates is 3-6\% of live births. There are different types and different degrees of long-term sequelae in $25-30 \%$ of live births, which is the important disease that affects the life quality of children (2). The diagnosis is based on consciousness, muscular tension, change of primitive reflex, convulsion, disease course and prognosis. HIBD is divided into mild, moderate and severe degrees, however, laboratory tests for diagnosis are currently insufficient.

Hypoxia ischemia can activate a series of biological chain reactions including affecting the oxidative phosphorylation of glucose, rapid depletion of ATP in cells, accumulation of lactic acid, depolarization of cell membrane, release of excitatory amino acid and accumulation of $\mathrm{Na}^{+}, \mathrm{Ca}^{2+}, \mathrm{H}_{2} \mathrm{O}$, free radical and free fatty acid (FFA) in cells, to cause cellular swelling and cell death (3). Hypoxia ischemia can decrease the synthesis of protein and adipose and increase their metabolic products such as urea nitrogen, creatinine, uric acid and FFA. Adipocyte fatty acid-binding protein (A-FABP) is a member of the fatty acid binding protein family. It is expressed in adipocytes and macrophages, as well as endothelial cells and blood. As a molecular chaperone of fatty acid, A-FABP is considered 
a thrifty gene that can promote the transfer of fatty acid and energy storage. When the body experiences stress such as starvation, the preserved energy is released for body utilization. A-FABP is an important regulatory factor of obesity, insulin resistance and metabolic syndrome and the expression of A-FABP can be induced by proliferator-activated receptor $\gamma$ (PPAR $\gamma$ ) agonist, insulin and fatty acid (4). However, the role and significance of A-FABP in HIBD have yet to be studied universally. As the hypoxia ischemia lengthens, the level of FFA increases in neonates with HIBD, and it is suggested that increased FFA can induce the expression of A-FABP to cause an increase of serum A-FABP.

In the present study, serum levels of A-FABP and FFA in 42 neonates with acute phase and recovery phase HIBD were detected, respectively, using the enzyme-linked immunosorbent assay (ELISA) and copper colorimetric method. The relationship between A-FABP, FFA level and severity of HIBD was analyzed, and the change of the above indicators in the same neonate at the acute and recovery phase was observed. The aim was to explore the relationship between A-FABP, FFA and severity of HIBD with acute phase and provide a diagnostic basis for diagnosis and prognosis of HIBD.

\section{Patients and methods}

Patients. In total 42 full-term neonates with HIBD admitted between January 2009 and January 2010 at the Department of Pediatric, Fourth Hospital of Hebei Medical University (Hebei, China) and Department of Pediatric, Cangzhou Central Hospital (Cangzhou, China) were selected. There were 31 male and 11 female cases, 17 cases of eutocia and 25 cases of cesarean delivery. The average gestational age was $38.8 \pm 1.33$ weeks, and the average weight was $3.15 \pm 0.51 \mathrm{~kg}$ at birth.

Criteria of diagnosis and clinical grading. The criteria of diagnosis and clinical stage used were as reported earlier (5). The neonate based on the following criteria were diagnosed as HIE: i) There was confirmed abnormal obstetric history causing fetal distress in the uterus, and severe fetal distress manifestation (fetal heart rate $<100 / \mathrm{min}$ for $>5 \mathrm{~min}$; and/or degree III amniotic fluid pollution) or obvious asphyxia history during delivery; ii) there was severe asphyxia during delivery, i.e. Apgar score $\leq 3$ at $1 \mathrm{st} \mathrm{min}, \leq 5$ at 5 th $\mathrm{min}$; and/or $\mathrm{pH} \leq 7.0$ in blood gas of umbilical artery; iii) there were neurological symptoms after birth, that persisted for $>24 \mathrm{~h}$, such as change of consciousness (over excitation, somnolence, coma), change of muscular tension (increase or decrease), abnormity of primitive reflexes (sucking reflex or moro reflex was weakened or disappeared), convulsion and brain stem symptom when seriously ill (change of respiratory rhythm, change of pupil, light reflex was slow or disappeared) and increase of bregma tension; and iv) the neonates with convulsion caused by electrolyte disturbance, intracranial hemorrhage and birth injury were excluded. The neonates with brain injury caused by intrauterine infection, genetic metabolic disease or other congenital diseases were excluded.

In addition, if by computed tomography scan there was encephaledema, there was diffuse low-density shadow complicated with narrowed encephalocoele in brain parenchyma. If

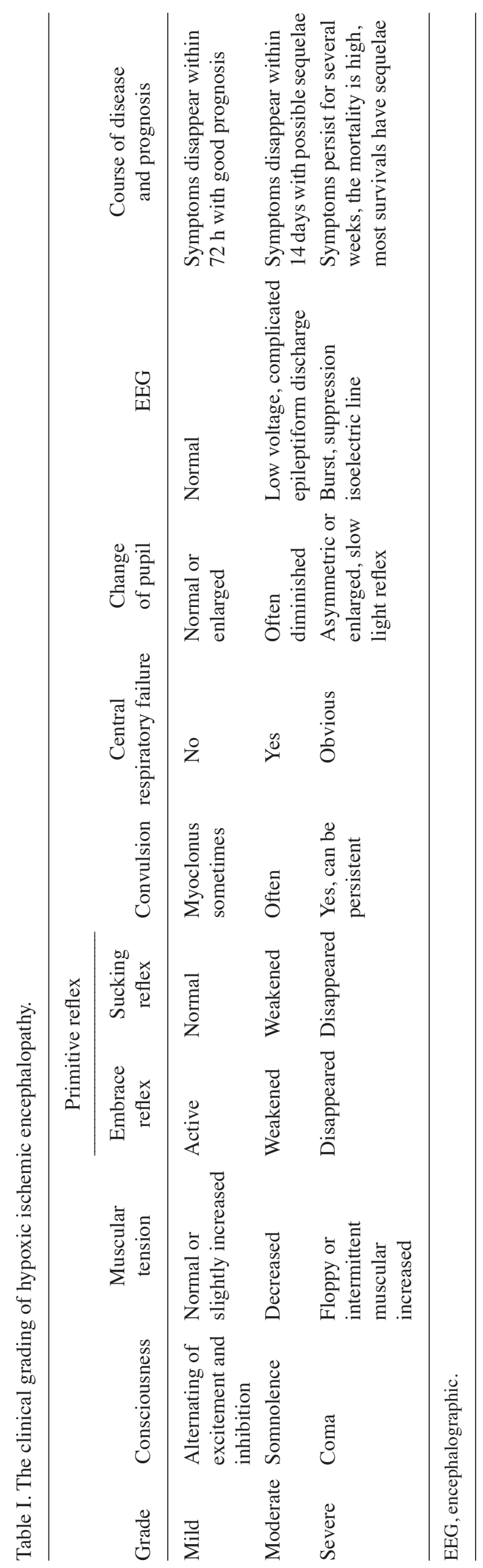


Table II. Clinical parameters of HIBD and normal neonates.

\begin{tabular}{|c|c|c|c|c|c|c|c|}
\hline Group & Control & Case & Mild & Moderate & Severe & $\mathrm{F}$ & P-value \\
\hline No. & 10 & 42 & 11 & 16 & 15 & & \\
\hline FA, weeks & $38.5 \pm 1.12$ & $38.8 \pm 1.33$ & $39 \pm 1.35$ & $38.5 \pm 1.22$ & $38.7 \pm 1.29$ & 0.759 & $>0.05$ \\
\hline $\mathrm{BW}, \mathrm{kg}$ & $3.29 \pm 0.52$ & $3.15 \pm 0.51$ & $2.94 \pm 0.55$ & $3.10 \pm 0.35$ & $3.37 \pm 0.56$ & 1.914 & $>0.05$ \\
\hline Male & 7 & 31 & 7 & 12 & 12 & & $>0.05$ \\
\hline Female & 3 & 11 & 4 & 4 & 3 & & $>0.05$ \\
\hline Eutocia & 4 & 17 & 6 & 4 & 7 & & $>0.05$ \\
\hline U-D & 6 & 25 & 5 & 12 & 8 & & $>0.05$ \\
\hline
\end{tabular}

The comparison is made with one-way ANOVA and two-independent sample tests (Mann-Whitney U). FA, fatal; BW, body weight; HIBD, hypoxic-ischemic brain damage.

basal ganglia and thalamus were injured there was bilateral symmetric high-density shadow, while the cerebral infarction showed low-density shadow in the corresponding blood supply area. The clinical grading of HIE is shown in Table I.

Inclusion criteria. i) Neonates were full-term (gestational age was between 37 and 42 weeks, birth weight between 2,500-4,000 g), Apgar score of included neonates at 1st min was $>3$; ii) neonates did not receive cortical hormone treatment. The remaining inclusion criteria were the same as those for HIE. In total, 11 included cases were mild, 16 included cases were moderate and 15 included cases were severe.

Control group. Ten cases of neonates with similar gestational age and weight to the HIBD group were selected from the full-term neonates without hypoxia manifestation and cardiopulmonary disease at the same period. There were 7 male cases and 3 female cases, 4 cases of eutocia and 6 cases of cesarean delivery, the average gestational age was $38.5 \pm 1.12$ weeks, the average weight was $3.29 \pm 0.52 \mathrm{~kg}$ at birth (Apgar score was 9'-10'-10' or $\left.10^{\prime}-10^{\prime}-10^{\prime}\right)$.

\section{Methods}

Serum collection. Blood (2-3 ml) was collected from peripheral vein in HIBD and normal neonates within $72 \mathrm{~h}$ after the first visit and at 7 days after birth. The blood was routinely centrifuged at $1,000 \mathrm{x}$ g for $5 \mathrm{~min}$ to collect serum and later preserved at $-20^{\circ} \mathrm{C}$. The indicators in HIBD and normal neonates were detected at the same time. Informed consent was obtained from the families of neonates for serum collection.

Detection of serum A-FABP by ELISA. The reagent kit was provided by Adlitteram Diagnostic Laboratories (San Diego, CA, USA), and plate washing and absorbance detection were completed on a microplate reader. A-FABP standard solution $(100 \mu \mathrm{l})$, serum $(100 \mu \mathrm{l})$ and $50 \mu \mathrm{l}$ biotin-labeled A-FABP with specific anti A-FABP antibody-coated micropores were mixed. After incubation at $37^{\circ} \mathrm{C}$ for $1 \mathrm{~h}$, the plates were washed for $55 \mathrm{~min}, 50 \mu \mathrm{l}$ horse radish peroxidase-conjugated anti-biotin antibody and $50 \mu \mathrm{l}$ enzyme substrate solution were added for developing coloration. After $15 \mathrm{~min}$ the stopping buffer was added to terminate the reaction, and then optical density (OD) values of different wells were read at a wavelength of $450 \mathrm{~nm}$. $B$ was the OD value of standard and $B 0$ was the OD value of standard at time point 0 . The $\mathrm{B} / \mathrm{B} 0 \%$ value was set as a vertical coordinate and the concentration of standard was set as a horizontal coordinate to make a standard curve on the logarithmic coordinate paper. The concentration of A-FABP was determined according to the OD value of the sample on the standard curve.

Detection of FFA by copper colorimetric method. The copper colorimetric method was used to detect FFA according to the kit instructions (Nanjing Jiancheng Bioengineering Institute, Nanjing, China).

Detection of white blood cell, blood lipid, glucose and $C$-reactive protein. White blood cell, blood lipid, glucose and C-reactive protein were detected by Beckman Coulter LH 750, Beckman Coulter LX20 PRO detection and Beckman Immade detection (Beckman Coulter, Inc., Brea, CA, USA).

Statistical analysis. Data were analyzed using SPSS 11.5 (SPSS, Inc., Chicago, IL, USA). The data received normal distribution test (Kolmogorov-Smirnov test), normal distributional data were presented as mean \pm standard deviation, and the difference was analyzed by t-test and variance analysis. Non-normal distributional data were presented as median ( 25 percentile, 75 percentile), the difference was analyzed by the rank sum test and the inspection level was $\mathrm{a}=0.05 . \mathrm{P}<0.05$ was considered to indicate a statistically significant difference.

\section{Results}

Clinical data. The gender composition, the proportion of cesarean delivery, average gestational age, and birth weight in three HIBD neonate groups were not statistically different compared to normal neonates (Table II).

White blood cell count and serum $C$-reactive protein (CRP) in HIBD neonates at acute stage. The white blood cell count in HIBD neonates $\left(16.27 \pm 1.26 \times 10^{9} / 1\right)$ was significantly higher than that of normal neonates $\left(8.53 \pm 2.98 \times 10^{9} / 1\right)(\mathrm{P}<0.01)$. However, serum CRP in HIBD and normal neonates were in the normal range $(\mathrm{CRP}<8 \mathrm{mg} / \mathrm{l}$ ) (in both groups, the infectious 
Table III. Count of WBC and the content of C-reactive protein in the acute stage of the HIBD and normal neonates.

\begin{tabular}{lcccr}
\hline Group & Control & Case & t-test & P-value \\
\hline No. & 10 & 42 & & \\
WBC $\left(\mathrm{x} 10^{9} / \mathrm{l}\right)$ & $8.53 \pm 2.98$ & $16.27 \pm 1.26$ & -4.919 & $<0.01$ \\
CRP $(\mathrm{mg} / \mathrm{l})$ & $<8$ & $<8$ & & $>0.05$ \\
\hline
\end{tabular}

The comparison is made with the independent-samples t-test. WBC, white blood cell; HIBD, hypoxic-ischemic brain damage; CRP, C-reactive protein.

Table IV. Levels of blood-lipid and BG in acute stage of HIBD and normal neonates.

\begin{tabular}{|c|c|c|c|c|}
\hline Group & Control & Case & $t / z$ & P-value \\
\hline No. & 10 & 42 & & \\
\hline $\begin{array}{l}\mathrm{TC} \\
\mathrm{mmol} / 1\end{array}$ & $2.72 \pm 0.97$ & $2.42 \pm 0.89$ & 0.941 & $>0.05$ \\
\hline $\begin{array}{l}\text { TG, } \\
\mathrm{mmol} / \mathrm{l}\end{array}$ & $0.57(0.29-0.80)$ & $0.60(0.37-1.15)$ & -0.965 & $>0.05$ \\
\hline $\begin{array}{l}\text { HDL, } \\
\mathrm{mmol} / 1\end{array}$ & $0.81 \pm 0.18$ & $0.65 \pm 0.23$ & 2.037 & $<0.05$ \\
\hline $\begin{array}{l}\text { LDL, } \\
\mathrm{mmol} / 1\end{array}$ & $1.45 \pm 0.70$ & $1.19 \pm 0.55$ & 1.254 & $>0.05$ \\
\hline ApoA, g/l & $0.80(0.60-0.85)$ & $0.71(0.70-0.80)$ & -0.649 & $>0.05$ \\
\hline ApoB, g/l & $0.33 \pm 0.16$ & $0.35 \pm 0.14$ & -0.232 & $>0.05$ \\
\hline $\begin{array}{l}\mathrm{BG} \\
\mathrm{mmol} / \mathrm{l}\end{array}$ & $3.90 \pm 1.12$ & $3.35 \pm 1.20$ & 1.207 & $>0.05$ \\
\hline
\end{tabular}

The comparison is made with the independent-samples t-test. HIBD, hypoxic-ischemic brain damage; TC, total cholesterol; TG, triglyceride; HDL, high-density lipoprotein; LDL, low-density lipoprotein; Apo, apolipoprotein; BG, blood glucose.

factor was excluded, the increase of white blood cell count in HIBD neonates was considered to be related to the stress reaction caused by hypoxia ischemia) (Table III).

Blood lipid and glucose levels in HIBD neonates at acute stage. High-density lipoprotein (HDL) level in HIBD neonates $(0.65 \pm 0.23 \mathrm{mmol} / \mathrm{l})$ was significantly decreased compared with normal neonates $(0.81 \pm 0.18 \mathrm{mmol} / \mathrm{l})(\mathrm{P}<0.01)$. The other blood lipid parameters and blood glucose level were not different from normal neonates (Table IV).

Serum A-FABP level in HIBD neonates at acute stage. Serum A FABP content in overall HIBD neonates at acute stage was $21.61(14.96,37.67) \mathrm{ng} / \mathrm{l}$, which was significantly higher than $13.41(9.64,17.46) \mathrm{ng} / \mathrm{l}$ in the normal neonates $(\mathrm{P}<0.05)$. The serum A-FABP level in severe HIBD neonates was significantly higher than mild HIBD, moderate HIBD and normal neonates $(\mathrm{P}<0.05)$. There was no difference between the mild HIBD and moderate HIBD neonates (Fig. 1).

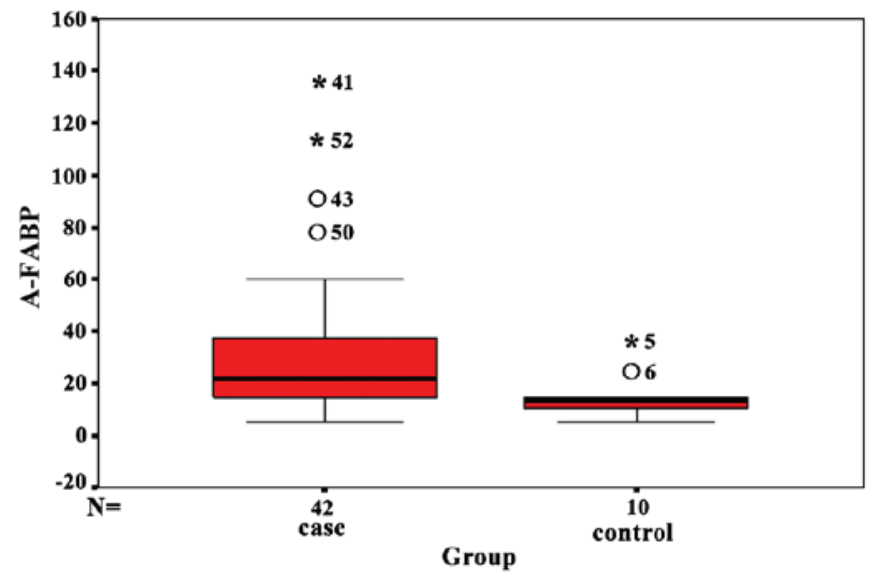

Figure 1. Serum adipocyte fatty acid-binding protein (FABP) levels in acute stage of hypoxic-ischemic brain damage neonates in comparison to the normal neonates $\left({ }^{*} \mathrm{P}<0.05\right)$.

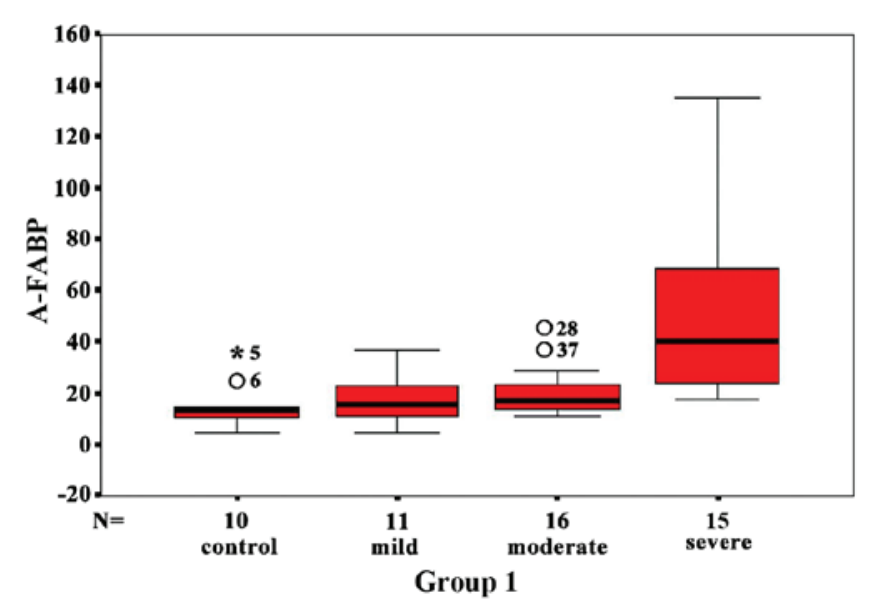

Figure 2. Serum adipocyte fatty acid-binding protein (FABP) levels in the acute stage. " Severe vs. control, mild, moderate $(\mathrm{P}<0.05)$.

Serum FFA level in HIBD neonates at acute stage. The overall serum FFA level in HIBD neonates at the acute stage was significantly higher than that of normal neonates $(\mathrm{P}<0.05)$. The serum FFA levels in mild, moderate and severe HIBD neonates were significantly higher than those of normal neonates $(\mathrm{P}<0.05)$. However, serum FFA level was not different among mild, moderate and severe HIBD neonates (Fig. 2).

Changes of A-FABP and FFA levels at recovery stage compared with acute stage. The overall A-FABP in HIBD neonates at the recovery stage was significantly decreased compared to the acute stage $(\mathrm{P}<0.05)$, which was significant in severe HIBD neonates $(\mathrm{P}<0.05)$. A-FABP levels in the mild and moderate HIBD neonates at recovery stage were decreased compared with the acute stage, however there was no statistical difference (Fig. 3). The overall FFA content in HIBD neonates at the recovery stage was decreased, however there was no statistical difference compared to the acute stage.

Correlation of serum A-FABP and FFA in HIBD neonates at the acute and recovery stages. Serum A-FABP level and FFA levels in HIBD neonates at the acute stage were positively 


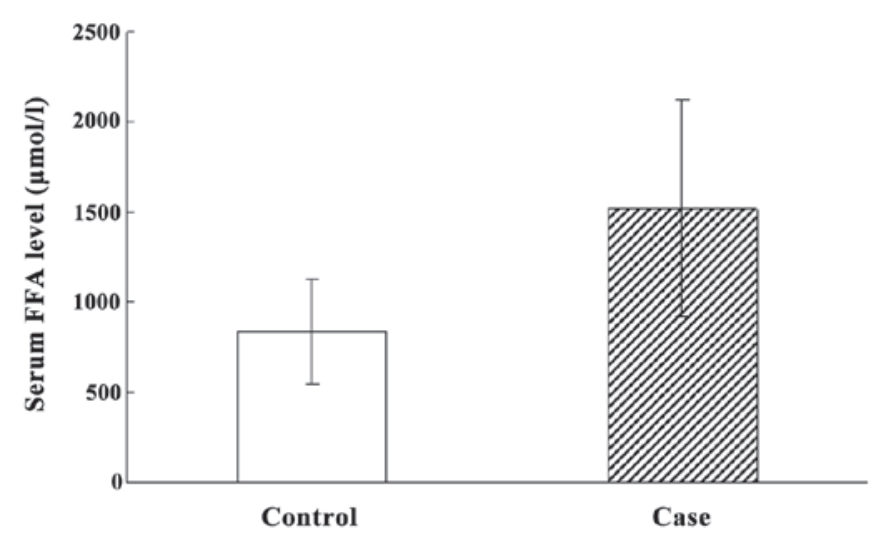

Figure 3. Serum free fatty acid (FFA) levels in the acute stage of hypoxic-ischemic brain damage neonates in comparison to the normal neonates $(\mathrm{P}<0.01)$.

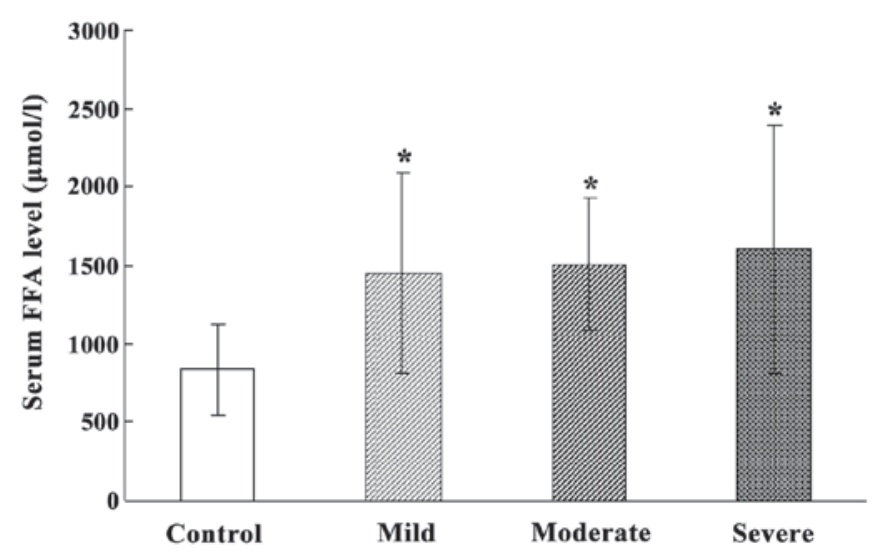

Figure 4. Serum free fatty acid (FFA) levels in the acute stage. "Severe, moderate, mild vs control $(\mathrm{P}<0.05)$.

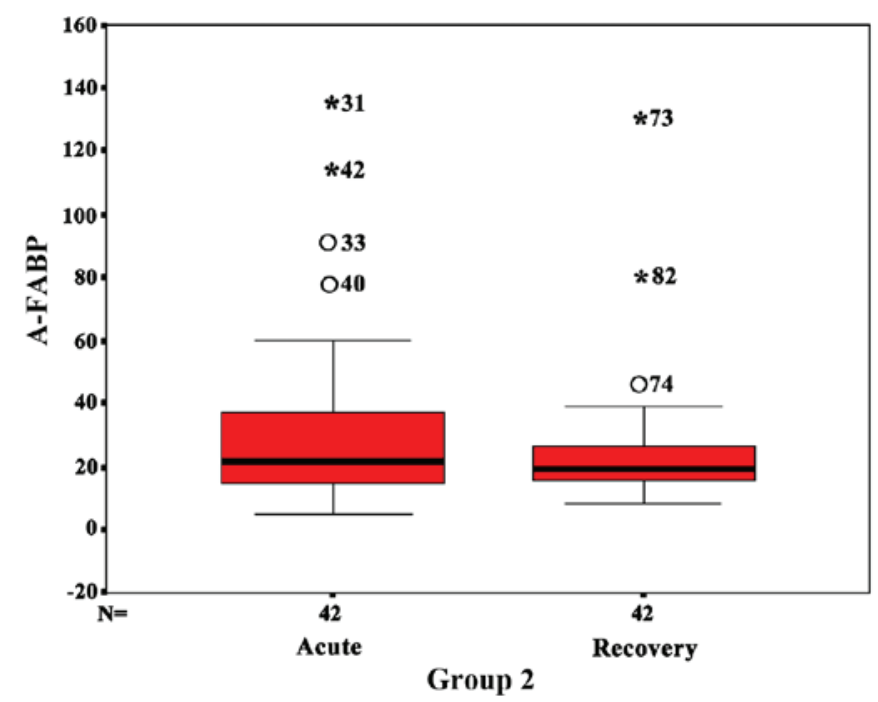

Figure 5. Comparison of serum adipocyte fatty acid-binding protein (FABP) levels in the acute stage in comparison to the recovery stage ( $(\mathrm{P}<0.05)$.

correlated, with the correlation coefficient as $\mathrm{r}=0.369(\mathrm{P}<0.05)$. However, there was no correlation at the recovery stage (Figs. 4-6).

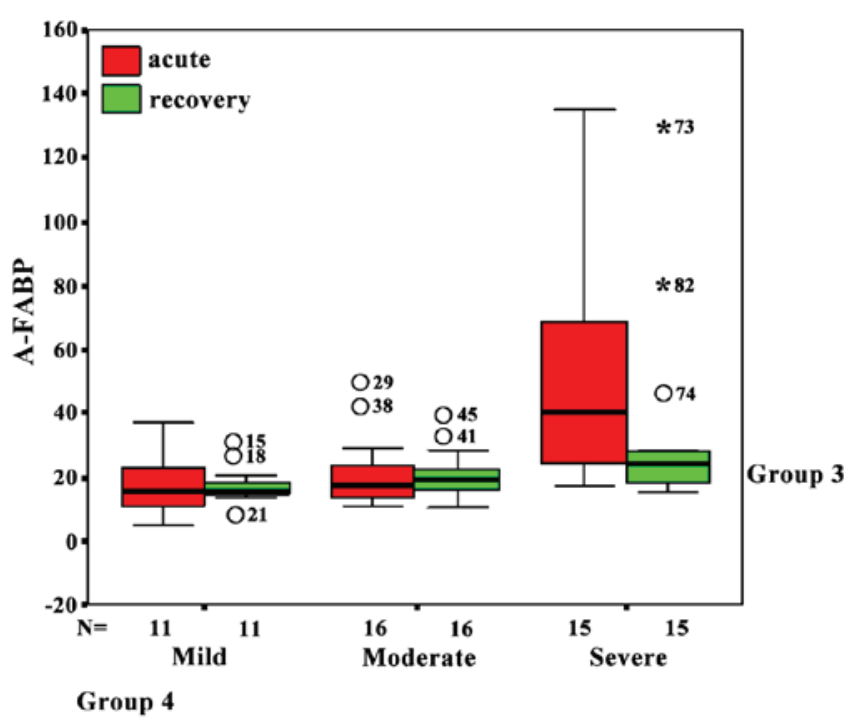

Figure 6. Comparison of serum adipocyte fatty acid-binding protein (FABP) levels. "Acute stage vs recovery stage $(\mathrm{P}<0.05)$.

\section{Discussion}

HIBD of neonates is important in perinatal nervous system disease, and severe HIBD neonates leads to serious complications of non-reversible nervous system sequelae. Hypoxia is the key link of pathogenesis, while a series of cascade reactions follow hypoxia. Interactions of several mechanisms cause degeneration and necrosis, even softening of brain tissue and further induce non-reversible brain injury (6). Statistics indicate 18-20 million live neonates, and the occurrence rate of HIE as $\sim 3-6 \%$ of live neonates, $15-20 \%$ of whom die at the neonatal period, while different types and degrees of long-term sequelae are present in $25-30 \%$ of survivals. Thus, this disease affects the quality of life of children (2). At present, the diagnosis of HIBD has been primarily based on medical history, clinical manifestation, blood gas analysis and imageological examination. Certain criteria (7) are apparently extremely rigid, without flexibility, leading to an appropriate diagnosis. The diagnostic criteria at home and abroad lack objective and effective laboratory examination, affecting the early diagnosis and appropriate observation of the degree of injury and therapeutic effects in HIBD neonates (8).

When there is hypoxia ischemia, the cell membrane of neurons is depolarized and intracellular $\mathrm{Ca}^{2+}$ concentration is rapidly increased. Hypoxia ischemia can cause the release of a large number of oxygen radicals and the participation of free radicals can degrade membrane phospholipid to release a large number of FFA (9). It has been found that phospholipase is activated and FFA is released in moderate and severe asphyxia Wistar rat (10). FFA level in the cerebral cortex in HIBD neonates becomes elevated with prolonging of the hypoxia ischemia (11). In the present study, serum FFA content level in HIBD neonates at acute stage was significantly higher than that in normal neonates, and the serum FFA level was also increased with aggravation of the degree of hypoxia Overall serum FFA and FFA levels in moderate and severe neonates was reduced, whereas serum FFA was increased in the mild neonates. Considering that the symptoms of mild HIBD 
neonates were rapidly recovered and the body weight increased satisfactorily, FFA increase may be affected by sufficient diet, breast milk or powered milk.

A-FABP mainly exists in adipocytes and macrophages, the main function of which is to regulate lipid metabolism. It regulates oxidation of fatty acid and metabolism of phospholipid and triglyceride in several steps including assimilation, convey, esterification and $\beta$ oxidation (12). PPAR $\gamma$ activator, insulin, FFA and oxidized low-density lipoprotein can upregulate A-FABP expression $(13,14)$. A-FABP gene knockout mice manifest as increased fat, decreased lipolysis, increased aerobic oxidation and reduced insulin resistance, indicating that A-FABP regulates energy metabolism by regulating fatty acid metabolism (15). Considering that the long-chain FFA can induce the expression of A-FABP, we hypothesized that if FFA was increased in HIBD neonates, A-FABP expression would also be increased in HIBD neonates. In the present study, the results verified the hypothesis as the overall serum A-FABP in HIBD neonates at acute stage was significantly higher than that in normal neonates. Serum A-FABP level in severe HIBD neonates was significantly higher than than in mild and moderate HIBD neonates. The overall A-FABP in HIBD neonates at the recovery stage was significantly decreased compared to the acute stage, which was significant in severe HIBD neonates. The overall serum A-FABP and FFA levels in HIBD neonates at the acute stage were positively correlated.

In 2006, A-FABP was initially identified as a blood circulation protein (16). However, there is no specific basis that verifies that A-FABP is released by adipocytes and macrophages or regulated by some regulatory mechanism. Additionally, there was secretion signal sequence in the primary and tertiary structures of A-FABP $(17,18)$. It was shown that the protein lacking the exocytosis positioning signal sequence can pass plasma membrane by an unconventional secretion mechanism (19). Rat adipocytes lack secretion signal sequences, the release of various proteins was completed by vesicle in rat, and A-FABP was found in vesicle (20). There was also A-FABP in the vesicle fragment of human cell supernatant (21). The abovementioned results have shown that at least part of A-FABP can enter the blood circulation by vesicle of adipocytes. Although the mechanism of how FABP4 enters blood circulation remains to be determined, it has been demonstrated that A-FABP was significantly increased in patients with lipid metabolic diseases such as simple obesity, metabolic syndrome $(22,23)$, familial hyperlipidemia (24), non-alcoholic cirrhosis (25) and coronary heart disease $(26,27)$. Recent findings have shown that although there was no A-FABP in the endothelial cells of small cerebral vessels, there was A-FABP in endothelial cells of blood capillaries and small veins in myocardium, skeleton muscles and tissue beside the large airway (28). Thus we considered that endothelial cells were one source of blood FABP4.

Different results have been identified regarding blood lipid level in asphyxia neonates. In the detection of blood lipid leveld in hypoxia asphyxia neonates by Yu et al (29), serum total cholesterol and triglyceride were significantly increased at the early stage of asphyxia, which was more significant in severe neonates. Time-course of the blood lipid level in asphyxia neonates, triglyceride (TG) and apolipoprotein A1 levels were significantly increased after birth, while HDL cholesterol (HDL-C) was decreased. This finding was not related to asphyxia degree, and there was no significant change of other indicators (30). In the present study, TG was increased and HDL-C was decreased in the HIBD neonates. These results indicate that although there was dyslipidemia in HIBD neonates, the conventional lipid detection cannot be applied as a specific laboratory indicator for HIBD. Serum FFA and FABP4 were significantly increased in HIBD neonates at the acute stage, which were increased with the increase in degree of injury, and decreased as the recovery of disease condition.

In conclusion, the results have shown that serum FFA and A-FABP were increased in HIBD neonates at the acute stage, and the serum level of A-FABP and FFA acute stage can reflect the severity of HIBD. The detection of serum A-FABP and FFA cannot only be applied as the indicators for the early diagnosis of HIBD, but also provides a basis for the clinical evaluation of HIBD treatment.

\section{Acknowledgements}

The present study was supported by the National Natural Science Foundation of China (no. 31271149), and the Foundation for high-level talented person of Hebei Province (no. A201400544) Major Projects of Education Department of Hebei (no. ZD2016010).

\section{References}

1. Ilyukhina VA, Kataeva GV, Korotkov AD and Chernysheva EM: [Oxygen-dependent energy deficit as related to the problems of ontogenetic development disorders and human sociobiological adaptation (theoretical and applied aspects)]. Zh Evol Biokhim Fiziol 51: 77-87, 2015.

2. Karadag N, Beken S, Dilli D, Zenciroglu A and Okumus N: Successful hypothermia treatment of hypoxic-ischemic encephalopathy in a neonate with epidermolysis bullosa. Indian J Pediatr 81: 803-804, 2014.

3. Strasser A, Stanimirovic D, Kawai N, McCarron RM and Spatz M: Hypoxia modulates free radical formation in brain microvascular endothelium. Acta Neurochir Suppl 70: 8-11, 1997.

4. Kralisch S, Klöting N, Ebert T, Kern M, Hoffmann A, Krause K, Jessnitzer B, Lossner U, Sommerer I, Stumvoll M, et al: Circulating adipocyte fatty acid-binding protein induces insulin resistance in mice in vivo. Obesity (Silver Spring) 23: 1007-1013, 2015.

5. Rafay MF, Cortez MA, de Veber GA, Tan-Dy C, Al-Futaisi A, Yoon W, Fallah S and Moore AM: Predictive value of clinical and EEG features in the diagnosis of stroke and hypoxic ischemic encephalopathy in neonates with seizures. Stroke 40: 2402-2407, 2009.

6. Busl KM and Greer DM: Hypoxic-ischemic brain injury: Pathophysiology, neuropathology and mechanisms. NeuroRehabilitation 26: 5-13, 2010.

7. No authors listed: Use and abuse of the Apgar score. Committee on Fetus and Newborn, American Academy of Pediatrics, and Committee on Obstetric Practice, American College of Obstetricians and Gynecologists. Pediatrics 98: 141-142, 1996.

8. Tataranno ML, Perrone S and Buonocore G: Plasma biomarkers of oxidative stress in neonatal brain injury. Clin Perinatol 42: 529-539, 2015.

9. Niatsetskaya ZV, Sosunov SA, Matsiukevich D, UtkinaSosunova IV, Ratner VI, Starkov AA and Ten VS: The oxygen free radicals originating from mitochondrial complex I contribute to oxidative brain injury following hypoxia-ischemia in neonatal mice. J Neurosci 32: 3235-3244, 2012.

10. Gardiner M, Nilsson B, Rehncrona S and Siesjö BK: Free fatty acids in the rat brain in moderate and severe hypoxia. J Neurochem 36: 1500-1505, 1981.

11. Siesjö BK: Cerebral circulation and metabolism. J Neurosurg 60: 883-908, 1984 
12. Chmurzyńska A: The multigene family of fatty acid-binding proteins (FABPs): Function, structure and polymorphism. J App Genet 47: 39-48, 2006.

13. Glatz JF and van der Vusse GJ: Cellular fatty acid-binding proteins: Their function and physiological significance. Prog Lipid Res 35: 243-282, 1996.

14. Coe NR and Bernlohr DA: Physiological properties and functions of intracellular fatty acid-binding proteins. Biochim Biophys Acta 1391: 287-306, 1998.

15. Hotamisligil GS, Johnson RS, Distel RJ, Ellis R, Papaioannou VE and Spiegelman BM: Uncoupling of obesity from insulin resistance through a targeted mutation in aP2, the adipocyte fatty acid binding protein. Science 274: 1377-1379, 1996.

16. Engl J, Ciardi C, Tatarczyk T, Kaser S, Laimer M, Laimer E, Weiss H, Aigner F, Molnar C, Tilg H, et al: A-FABP - a biomarker associated with the metabolic syndrome and/or an indicator of weight change? Obesity (Silver Spring) 16: 1838-1842, 2008.

17. Veerkamp JH and Maatman RG: Cytoplasmic fatty acid-binding proteins: Their structure and genes. Prog Lipid Res 34: 17-52, 1995.

18. Reese-Wagoner A, Thompson J and Banaszak L: Structural properties of the adipocyte lipid binding protein. Biochim Biophys Acta 1441: 106-116, 1999.

19. Radisky DC, Stallings-Mann M, Hirai Y and Bissell MJ: Single proteins might have dual but related functions in intracellular and extracellular microenvironments. Nat Rev Mol Cell Biol 10: 228-234, 2009

20. Aoki N, Jin-no S, Nakagawa Y, Asai N, Arakawa E, Tamura N, Tamura $\mathrm{T}$ and Matsuda $\mathrm{T}$ : Identification and characterization of microvesicles secreted by 3T3-L1 adipocytes: redox- and hormone-dependent induction of milk fat globule-epidermal growth factor 8-associated microvesicles. Endocrinology 148: 3850-3862, 2007.

21. Miyake T, Ogawa E, Mikoshiba A, Kobayashi A, Hosoe H, Kashiwabara S, Uhara H, Owada $\mathrm{Y}$ and Okuyama R: Epidermal-type FABP is a predictive marker of clinical response to systemic treatment and ultraviolet therapy in psoriatic skin lesions. J Dermatol Sci 68: 199-202, 2012.
22. Lamounier-Zepter V, Look C, Alvarez J, Christ T, Ravens U, Schunck WH, Ehrhart-Bornstein M, Bornstein SR and Morano I: Adipocyte fatty acid-binding protein suppresses cardiomyocyte contraction: A new link between obesity and heart disease. Circ Res 105: 326-334, 2009.

23. Stejskal D and Karpisek M: Adipocyte fatty acid binding protein in a Caucasian population: A new marker of metabolic syndrome? Eur J Clin Invest 36: 621-625, 2006.

24. Cabré A, Lázaro I, Cofán M, Jarauta E, Plana N, Garcia-Otín AL, Ascaso JF, Ferré R, Civeira F, Ros E, et al: FABP4 plasma levels are increased in familial combined hyperlipidemia. J Lipid Res 51: 1173-1178, 2010.

25. Milner KL, van der Poorten D, Xu A, Bugianesi E, Kench JG, Lam KS, Chisholm DJ and George J: Adipocyte fatty acid binding protein levels relate to inflammation and fibrosis in nonalcoholic fatty liver disease. Hepatology 49: 1926-1934, 2009.

26. Karbek B, Özbek M, Bozkurt NC, Ginis Z, Güngünes A, Ünsal IÖ, Cakal E and Delibası T: Heart-type fatty acid binding protein (H-FABP): Relationship with arterial intima-media thickness and role as diagnostic marker for atherosclerosis in patients with 1mpaired glucose metabolism. Cardiovasc Diabetol 10: 37, 2011.

27. Doi M, Miyoshi T, Hirohata S, Nakamura K, Usui S, Takeda K, Iwamoto M, Kusachi S, Kusano $\mathrm{K}$ and Ito $\mathrm{H}$ : Association of increased plasma adipocyte fatty acid-binding protein with coronary artery disease in non-elderly men. Cardiovasc Diabetol 10: 44, 2011.

28. Rueda-Valencia ML, Infante S, Campos M, Belendez C and Saavedra LJ: Trimethoprim-sulfamethoxazole-induced DRESS syndrome in a 4-year-old child. Ann Allergy Asthma Immunol 116: 366-367, 2016.

29. Yu T, Kui LQ and Ming QZ: Effect of asphyxia on non-protein-bound iron and lipid peroxidation in newborn infants. Dev Med Child Neurol 45: 24-27, 2003.

30. Barrera-de León JC, Cervantes-Munguía R, Vásquez C, Higareda-Almaraz MA, Bravo-Cuellar A and González-López L: Usefulness of serum lipid peroxide as a diagnostic test for hypoxic ischemic encephalopathy in the full-term neonate. J Perinatol 33: $15-20,2013$. 